\section{CPS-091 CURRENT STATE OF RETREATMENT OF HEPATITIS C INFECTION IN PATIENTS WHOM PRIOR THERAPY FAILED IN A HEPATITIS REFERRAL CENTRE}

JF Meyer*, C San, V Siorat, S Kabiche, JE Fontan. Hôpital Jean Verdier, Pharmacy, Bondy, France

10.1136/ejhpharm-2019-eahpconf.240

Background The World Health Organisation calls for the eradication of the hepatitis C virus (HCV) by 2030. Direct-acting antivirals (DAAs) drugs promise shorter treatment times, much higher cure rates and fewer side effects. However, some patients failed to achieve sustained virological response (SVR) after DAAs regimens. Experts recommend retreatment based on an individual decision of the multidisciplinary team (MDT).

Purpose The aim of this study was to describe the cases of our hospital's patients who failed to achieve SVR after DAAs regimens.

Material and methods The study of the MDT reports between February 2014 and July 2018 allowed us to identify retreated patients who failed to achieve SVR after DAAs regimens. Patient information was collected based on the analysis of consultations' reports of the hepatology department: age, sex, viral genotype, co-infection with hepatitis $B$ virus (HBV) and/or human immunodeficiency virus (HIV), cirrhosis, presumed cause of failure of the first treatment with DAA.

Results Of the 385 cases evaluated by the MDT, 12 patients were identified. Patients mean age was $57 \pm 12$ years, sex ratio $\mathrm{M} / \mathrm{F}$ was $1: 4$, four patients were cirrhotic, one was coinfected with HBV and two were co-infected with HIV. The genotypes found were: $1(n=4), 2(n=2), 3(n=2)$ and 4 $(n=4)$. First DAA treatment was either combinations of NS5B + NS5A inhibitors (such as sofosbuvir with daclatasvir/ ledispavir/velpatasvir, $\mathrm{n}=8$ ), or NS5A+NS3 inhibitors (grazoprevir/elbasvir or paritaprevir/ombitasvir, $n=3$ ) or NS5B +NS5A+NS3 inhibitors (dasbuvir/ombitasvir/paritaprevir, $\mathrm{n}=1$ ). Four treatments were associated with ribavirine. The presumed cause of failures was HCV resistance to NS5A inhibitors, since the other causes (non-compliance, drug interactions, re-infection, premature discontinuation) had been discarded. During retreatment, the duration of treatment was lengthened and/or ribavirin was added. The molecules used for retreatment were NS5B and NS3 inhibitors in 2016 and 2017 (simeprevir/sofosbuvir, $\mathrm{n}=2$ ). In 2018, NS5B+NS5A inhibitors associated with ribavirine (sofosbuvir/velpatasvir, $\mathrm{n}=1$ ), NS5B+NS5A+NS3 inhibitors (glecaprevir/pibrentasvir/ sofosbuvir with ribavirine $\mathrm{n}=4$, sofosbuvir/voxilaprevir/velpatasvir $\mathrm{n}=4$ ) and NS5A+NS3 (glecaprevir/pibrentasvir, $\mathrm{n}=1$ ) were used.

Conclusion Failed SVR were mainly caused by NS5A mutations. Second-generation DAAs marketing approval has allowed the retreatment of several patients. Therapeutic strategies for retreatment comply with European Association of the Study of the Liver guidelines. However, these patients should be monitored closely to evaluate SVR.

\section{REFERENCES AND/OR ACKNOWLEDGEMENTS}

http://www.easl.eu/medias/cpg/2018/EASL\%20Recommendations\%20on\%20Treatment $\% 20$ of\%20Hepatitis\%20C\%202018/ English-report.pdf

No conflict of interest.
4CPS-092 PREVALENCE OF POLYPHARMACY IN PATIENTS WITH HUMAN IMMUNODEFICIENCY VIRUS INFECTION

C Orallo Luna, J Fra Yáñez, L Becerra Ingerto, L Gómez de Segura liriarte, N González Sánchez, P Puente Martín, M Lamas Lopez*. Hospital Universitario San Agustín, Hospital Pharmacy, Avilés- Asturias, Spain

10.1136/ejhpharm-2019-eahpconf.241

Background Due to the introduction of highly active antiretroviral therapy (HAART), the percentage of older HIV-positive patients is growing, with an increase in comorbidities and chronic medication. Nowadays, patients over 50 years are considered as an elderly population because of the age-related weakening of the immune system.

Purpose To determine the prevalence of polypharmacy in HIVpositive individuals treated with antiretroviral therapy in a regional hospital. Another outcome is to quantify the number of chronic medications in patients older than 50 years compared to patients younger than 50 .

Material and methods Observational, retrospective study including HIV-positive patients with active antiretroviral therapy in January 2018. Exclusion criteria were: patients without clinical follow-up and post-exposure prophylaxis (PEP). The variables, collected from the electronic medical records and the electronic prescribing system, were: sex, age and chronic treatment. Polypharmacy was defined as simultaneous prescription of $\geq 6$ active principles, including antiretroviral therapy. 'Major polypharmacy', described as $\geq 11$ active principles, was also analysed. The statistical analysis was performed using SPSS Statistic.

Results Two-hundred and thirteen patients were included, 73\% were men and $27 \%$ women. The mean age was $51 \pm 11$ years. It is noteworthy that $60 \%$ of patients were older than 50 years. The prevalence of polypharmacy was 50\%. Likewise, the prevalence of 'major polypharmacy' was nearly $11 \%$. The mean number of drugs per patient (including HAART and concomitant medication) was significantly higher in the elderly group $(7.0 \pm 2.8$ versus $5.3 \pm 2.5)$. The most frequently prescribed treatments were: anxiolytics and hypnotics $(31 \%)$, antihypertensives (21\%), lipid-lowering agents (20\%) and antidepressant drugs (17\%).

Conclusion The prevalence of polypharmacy was high and similar to other studies, especially in elderly patients. It is necessary to develop specific health measures to help pharmacotherapy optimisation in this group of patients.

\section{REFERENCE AND/OR ACKNOWLEDGEMENTS}

Morillo-Verdugo R, Robustillo-Cortes M, Sanchez-Rubio J, et al. Prevalence and pharmacotherapeutic complexity of polypharmacy in HIV+ patients in Spain: point study. Eur J Hosp Pharm 2018;25:A249-A250.

https://ejhp.bmj.com/content/25/Suppl_1/A249.2

No conflict of interest.

\section{CPS-093 PERSISTENCE OF AN ANTIRETROVIRAL THERAPY IN HUMAN IMMUNODEFICIENCY VIRUS PATIENTS IN A TERTIARY LEVEL HOSPITAL}

A Pinilla Rello*, H Navarro Aznarez, A Magallón Martínez, B Abad Bañuelos, Á Arias Sánchez, MP Olier Martínez, A Gasso Sánchez, MR Abad Sazatornil. Universitary Miguel Servet Hospital, Hospital Pharmacy, Zaragoza, Spain

\subsection{6/ejhpharm-2019-eahpconf.242}

Background The guidelines of antiretroviral therapy (ART) for the human immunodeficiency virus (HIV) recommend starting 
with all the patients, regardless of the levels of CD4 lymphocytes and the symptomatology.

Purpose Persistence: time a patient remains with a treatment frome the beginning until the interruption, regardless of the reason. Aim of this research: comparison between the patients' persistence who different ART.

Material and methods Descriptive, transversal and retrospective research that includes all the patients who have started an ART for HIV, 2013-10 October 2018, and who have suffered a change in the therapy.

Variables: starting date, initial treatment, changing date and reason for the change. Analysis: SPSS Statistics.

Results Six-hundred and sixteen patients have started ART and $186(30.2 \%)$ of them have changed it.

Fifty-one $(27.4 \%)$ patients started ART with single tablet regimens (STRs), 40 (78.4\%) started with Tenofovir/Emtricitabine (TDF o TAF/FTC) and 11 (21,6\%) Abacavir/Lamivudine (ABC/3TC). Thirty-two 62.7\%) were with an integrase inhibitor (INI) as a third drug, and 19 (37.3\%) with no analogous (ITINN).

One-hundred and thirty-five (72.6\%) patients started with multiple tablet regimens (MTRs), $115(85.2 \%)$ TDF/FTC and $16(11.8 \%)$ ABC/3TC. Seventy-two (53.7\%) were with protease inhibitor (IP) as a third drug, 34 (25.4\%) ITINN and 28 (20.9\%) INI.

The median survival for STRs was 229 days (95\% CI 146.0 to 311.9 ) and 164 for MTRs (95\% CI 87.8 to 240.2), no statistically significant differences. Regarding the third drug, the median survival with INI was 103 days (95\% CI 65.0 to 140.9 ), 241 days with IP (95\% CI 162.1 to 319.9) and 265 days with ITINN (95\% CI 162.1 to 367.9). Between INI-IP and INI-ITNN, there were statistically significant differences.

One-hundred and five $(56.5 \%)$ patients changed their treatment because of toxicity, $48(25.8 \%)$ patients simplification, $19(10.2 \%)$ patients virologic failure, seven (3.8\%) patients due to interaction with their home treatment and seven (3.7\%) other causes. One-hundred and five patients changed ART by toxicity (39 of them (37.1\%) had as a third drug IP, 37 (35.2\%) ITINN and 29 (27.6\%) INI)

In 2013-2015, $20(16.8 \%)$ patients started STRs and in 2016-2018, 31 (46.3\%) patients started STRs.

Conclusion ART combinations with STRs have a longer survival in the treatment and in patients with IP as a third drug, a greater survival is observed. The main cause of ART in naïve patients is toxicity. There was a gradual rise in the use of STRs throughout the years studied.

\section{REFERENCES AND/OR ACKNOWLEDGEMENTS}

No conflict of interest.

\section{CPS-094 EFFECTIVENESS OF GLECAPREVIR/PIBRENTASVIR IN REAL-WORLD CLINICAL PRACTICE FOR CHRONIC HEPATITIS C INFECTION}

${ }^{1} M$ Rodriguez-Reyes*, ${ }^{1} \mathrm{JM}$ Sotoca-Momblona, ${ }^{2} \mathrm{M}$ Mensa-Vendrell, ${ }^{1} \mathrm{D}$ Soy-Muner. ${ }^{1}$ Hospital Clinic, Pharmacy Department, Barcelona, Spain; ${ }^{2}$ Hospital Plató, Pharmacy Department, Barcelona, Spain

10.1136/ejhpharm-2019-eahpconf.243

Background Glecaprevir/pibrentasvir (G/P) is a pangenotypic, once-daily, ribavirin-free direct-acting antiviral treatment for hepatitis $\mathrm{C}$ virus (HCV) infection in patients with and without compensated cirrhosis.

Purpose Our aim was to assess the effectiveness of G/P treatment in patients with HCV infection in clinical practice.

Material and methods Observational retrospective study in a tertiary hospital. Patients with $\mathrm{HCV}$ infection treated with $\mathrm{G} / \mathrm{P}$ between November 2017 and April 2018 were included.

Demographic data such as age, gender, race and adjusted morbidity group (AMG) were collected. AMG is a new morbidity tool adapted to the Spanish Healthcare System that classifies the population into four groups depending on the severity of their diseases.

Clinical registered variables were: transmission route of $\mathrm{HCV}$ infection, previous treatment status, stages of liver fibrosis, HCV genotype, baseline viral load, viral load measured after 4 weeks of treatment (VL4) categorised as undetectable, detectable below quantification (DBQ) and detectable above quantification (DAQ) with viral load $>15 \mathrm{IU} / \mathrm{mL}$, and sustained virological response defined as an undetectable HCV RNA level 12 weeks after stopping antiviral treatment (SVR12).

Results A total of 110 patients completed the treatment (55 \pm 12 years, $46 \%$ males, 95\% Europeans). The most frequent AMG were group $2(42 \%)$ and $3(23 \%)$. Transmission route was unknown in 57 patients $(52 \%)$, blood transfusion in 19 patients (17\%), intravenous drug use in 14 patients (13\%), nosocomial in 11 patients $(10 \%)$ and other routes in nine patients $(8 \%)$. Eighty-two patients $(75 \%)$ were naive. Fibrosis degree was F0-F1 in 86 patients (78\%), F2 in 20 (18\%), F3 in $2(2 \%)$ and $\mathrm{F} 4$ in $2(2 \%)$. Most common HCV genotypes were $1 \mathrm{~b}$ (72 patients, 65\%) and $1 \mathrm{a}$ (21 patients, 19\%). Mean baseline viral load was $3.18 \times 10^{6} \mathrm{IU} / \mathrm{mL}$.

VL4 was determined in 55 patients: in $75 \%$ of them it was undetectable, in $15 \%$ it was DBQ and in $10 \%$ it was DAQ. SVR12 was achieved by 109 patients (99\%) and in one patient results were not available due to loss of follow-up. Conclusion G/P is associated with high SVR12 rates in a realworld setting. Similar results were obtained in clinical trials.

\section{REFERENCES AND/OR ACKNOWLEDGEMENTS}

No conflict of interest.

\section{CPS-095 RESCUE OF PATIENTS INFECTED WITH HEPATITIS C VIRUS NOT RESPONDING TO INTERFERON-FREE THERAPIES}

M Sáez-Torres de Vicente*, MD López Malo de Molina, T López-Viñau López, L García Martinez. Hospital Reina Sofía, Pharmacy, Córdoba, Spain

10.1136/ejhpharm-2019-eahpconf.244

Background The new direct antiviral agents (DAAs) have substantially modified the situation of hepatitis $\mathrm{C}$ virus (HCV) infection patients, achieving very high viral response rates. ${ }^{1}$ However, in certain patients, treatment with DAAs fails.

Purpose Our objective was to assess the effectiveness of a new treatment with DAAs in patients with $\mathrm{HCV}$, in whom previous interferon-free therapies were ineffective.

Material and methods Retrospective descriptive observational study in which patients with HCV who were portrayed with DAAs between April 2013 and June 2018, were included. Demographic, analytical and clinical data were collected: age, sex, genotype, liver fibrosis $(\mathrm{F})$, treatment with previous DAAs, resistance profile, baseline viral load (VL) and VL 12 